Open Access

\title{
Heterogeneous expectations leading to bubbles and crashes in asset markets: Tipping point, herding behavior and group effect in an agent-based model
}

Sunyoung Lee and Keun Lee

\footnotetext{
* Correspondence: kenneth@snu.ac.kr An earlier version of this paper was presented at the 25th Annual EAEPE Conference which was held in Paris from 7 to 9 November 2013.

Department of Economics, Seoul National University, Seoul, South Korea
}

\begin{abstract}
Background: The traditional economic models are increasingly perceived as weak in explaining the bubbles and crashes in financial markets and the associated crisis. Thus, especially after the global financial crisis in 2008, agent-based model (ABM) is getting an attention as an alternative approach for a better understanding of complex dynamics of financial market.

Methods: This paper develops an ABM to replicate financial instability, such as bubbles and crashes in asset markets, by introducing a simple idea of 'heterogeneous expectation' and 'herding behavior' by which agents in different groups have different expectations about a 'tipping point' where they expect the price to stop rising anymore but to begins to fall.

Results: It is shown that, when the agents have different expectations on the tipping point, the collapse of the price does not emerge automatically, and price fluctuations are often small and even some (seemingly) flat intervals appear. We also verify the impact of the herding behavior by dividing agents into several groups of varying sizes but with the same expectations. By changing the size of groups, we establish that the more agents share the same expectations about the tipping point, the higher volatility of the asset price emerges.

Conclusions: We confirm that bubble and burst of prices are more like to emerge when heterogeneous expectations about prices are combined with herding behavior among agents, so that agents in the same group share the similar expectations about the price changes.
\end{abstract}

\section{Springer}

\section{Background}

The efficient market hypothesis (EMH) had emerged in the mid-1960s to gain general acceptance as a prominent financial theory. The main idea of the EMH is that asset prices are always at the correct value of the asset, markets move toward equilibrium, and after reaching equilibrium they remain in this state until influenced by an unexpected exogenous shock. Thus, according to this theory, financial markets cannot generate their own internal forces to disrupt an equilibrium, and large price changes are just the result of markets responding to new information from the outside or to changing fundamentals.

(c) 2015 Lee and Lee. Open Access This article is distributed under the terms of the Creative Commons Attribution 4.0 International License (http://creativecommons.org/licenses/by/4.0/), which permits unrestricted use, distribution, and reproduction in any medium, provided you give appropriate credit to the original author(s) and the source, provide a link to the Creative Commons license, and indicate if changes were made. 
Therefore, according to EMH, there is no room for asset price bubbles or crashes to occur. ${ }^{1}$

However, history and past data show that the EMH is not always successful in explaining phenomena in financial markets. From the Dutch tulip bubble in 1626, the British South Sea Company bubble, the French Mississippi Company bubble of the early 18th century, and the Japanese bubble in 1980s to recent U.S. sub-prime mortgage and the financial crisis of 2008, bubbles and crashes in financial markets have occurred and continued to occur.

In a broader context, the failure of the mainstream economic theory to predict financial crises has been pointed out (Colander et al. 2009; Buchanan 2009), such that while it has been partially successful in predicting events in the near future using past data, it has failed in the face of the changes of a much bigger scale. The theory of dynamic stochastic general equilibrium (DSGE) also has limitations due to its dependence on strong assumptions, such as perfect rationality of the representative agent and the predetermined equilibrium concept for analytic solutions. In addition, because they exclude crises of the type that have occurred before and that we are experiencing now, it is not possible to predict a crisis using these models. Now, there is a growing recognition that an alternative theory or model is needed to explain the types of events that conventional economic models have never sufficiently explained. Agent-based modeling $(\mathrm{ABM})$ has been proposed as an alternative (Farmer and Foley 2009; LeBaron 2006; The Economist 2010).

$\mathrm{ABM}$ is a computational methodology that allows an analyst to create, analyze, and experiment with artificial worlds composed of agents that interact within a specific environment. ${ }^{2}$ It is characterized by key assumptions such as bounded rationality of agents, routine-based or adaptive behavioral rules, heterogeneity of agents, and learning process (Yoon and Lee 2009). Namely, in contrast to the DSGE, ABM allows a high degree of heterogeneity of agents and takes a bottom-up approach which assigns particular behavioral rules to each agent and generate dynamic path of an economy out of interaction among agents. In this light, $\mathrm{ABM}$ is appropriate for analyzing the financial market as an outcome of heterogeneous agents and their interactions and for investigating economic phenomena such as financial crisis, which is hard to explain using mainstream economics tools.

Some previous studies have analyzed the financial markets based on ABM. The Santa Fe Artificial Stock Market, SF-ASM, is one of the earliest representative models. The SF-ASM model has evolved from the initial version of Palmer et al. (1994) and LeBaron et al. (1999) to the modified version by Ehrentreich (2004). Palmer et al. (1994) set up a simple stock market model where independent adaptive agents trade stock on a central market. They showed that price can display bubbles, crashes, and continued high trading volume. LeBaron et al. (1999) present an experimental computer simulated stock market to show that for some parameters the market generates interesting features, which appear to replicate some of those found in real financial time series data.

A growing number of models have been developed to consider the heterogeneity of the agents and interactions among them, such as Chiarella and Iori (2002), Chiarella et al. (2006), Chiarella et al. (2009), and Malek and Ezzeddine (2011). Chiarella and Iori (2002) show how the trading strategies of noise traders, fundamentalists and chartists have an effect on the price, bid-ask spreads, trading volume and volatility; Fundamentalists 
are agents who make trading decisions with a belief that an asset has its own intrinsic value (equilibrium price) at any point of time, whereas chartists use past price trends as basis for decisions with a belief that the history of the price changes is useful information for making meaningful predictions for the future price of the asset. They show that the presence of chartist plays a critical role in the volatility of price and trading volume, and investigate the correlation between them. Chiarella et al. (2009) set up the model with agents assumed to have three components of the expectation of future asset returns, namely fundamentalist, chartist and noise trader, and analyzed the impact of these three components of trading strategies on the statistical properties of prices and order flows. Through this model, it turns out that fat tails are caused by the chartist strategy. Malek and Ezzeddine (2011) consider three different types of investors; fundamental agents, irrational agents, and loss adverse agents, and show that irrational investors can explain the excess volatility of stock prices. They focus on the volatility puzzle which is hard to explain with traditional financial theories including efficient market hypothesis. Chiarella et al. (2006) consider a financial market with both a risky asset and a safe asset with a view to explain asset price and wealth dynamics as a result of the interaction between two groups of agents, fundamentalists and chartists.

Besides the papers which consider heterogeneity of the agents, the studies on asset market using ABM have been extended in a variety of ways. Harras and Sornette (2011) focus on the source of information. They endogenize three sources of information to the decisions of agents to show that a random sequence of the same news pushes price in one direction, and that through the coordination process among agents, the price reaches to an unsustainable level. Also, they show that once the agents have invested all their cash into the stock, just a little negative news can cause the price to collapse.

Taken together, the previous studies on asset market based on ABM mainly focused on the heterogeneity of agents and their interactions, and some of these studies were extended to consider the source of information that agents can access. Now, while the aim of the current study is also to explain the mechanisms of how bubbles and crashes emerge in asset markets with heterogeneous agents based on the ABM, our distinctions are as follows. First, while most of the previous literatures considered the heterogeneity of agents in forming expectations for future asset price or returns, and explained the dynamics of asset price as a consequence of the presence of chartists (Chiarella and Iori 2002; Chiarella et al. 2009), we expand upon this by considering the role of different expectations for the 'tipping point' by each agent as a cause of the collapse of the asset prices in the financial markets. As previous studies have pointed out, chartists can be expected to buy additional assets even at the high price level if they believe that the asset price will rise further. These behaviors of agents push the market price to a higher level, and bubbles can occur. However, during the process, if the price rises above certain level that the agent believes to be the maximum, the agent will change his behavior from buying to selling due to a concern for loss of capital. Namely, each agent has different or heterogeneous expectations about the 'tipping point' for the asset price. These expectations can affect the dynamics of asset price. However, so far, most of the previous studies have not considered this. In this paper, we reflect this aspect into the model to investigate how different expectations about tipping point could have an effect on the dynamics of an asset price. Furthermore, we 
also allow the herding behavior such that some agents share the same expectations about the price levels.

Second, we do not divide agents into either fundamentalists or chartists. In the real world, if agents have access to information about both the fundamental values of the asset and the historical price change data, they will use both of these to predict the future price rather than using just one type of information. Thus, we assume that each agent has the weight for each component used for anticipating the future prices. Third, we use simple but intuitive trading rules for each agent, rather than assuming certain types of expected utility functions such as CARA (Arthur et al. 1997; Chen and Yeh 2001; Lettau 1997) and CRRA (Bullard and Duffy 2001; LeBaron 2001; LeBaron 2006; Chiarella et al. 2006), to avoid adding unnecessary assumptions to derive simple demand function from it.

The ABM simulation in this paper is to show how the heterogeneous expectations across groups of agents about the tipping point affect price dynamics and maximum price level. It will be first shown in a benchmark model without grouping of agents where every single agent have different expectation that the collapse of the price does not emerge automatically, and price fluctuations are often small and even some (seemingly) flat intervals appear. However, this pattern of dynamics for asset price change when we reduce the heterogeneity in forming the expectations about tipping points and allow herding behavior among agents. In other words, we investigate how herding behaviors of agents can affect asset price dynamics by divide agents into several groups which share the same expectation about the tipping points, so that agents in the same group move together or collectively but agents in different groups behave differently. By changing the size of groups (number of agents in each group) or changing the number of groups, we will generate a case of extreme instability where the asset price fluctuates rapidly in large amount within a short period of time. Basically, price dynamics show higher volatility when more agents share same thresholds, which is the case of a smaller number of groups or larger size of members in each group. In sum, we show that bubble and burst of prices is more like to emerge when heterogeneous expectation about prices are combined with herding behavior among agents, so that agents in the same group share the similar expectations about the price changes.

This paper is organized as follows. In section The model, we present a basic model, and introduce the formations of the expectation for the asset price, trading rules, and equations for price determination. Section Simulation analysis provides the simulation results. Finally, section Concluding remarks provides a conclusion.

\section{The model}

At period 0, each agent is endowed with one unit of risky asset and some amount of cash which are randomly drawn from uniform distribution on the interval $[0, \bar{C}]$. We define the wealth of each agent at the initial period as

$$
\mathrm{w}_{\mathrm{i} 0}=\mathrm{c}_{\mathrm{i} 0}+\mathrm{p}_{0} \mathrm{a}_{\mathrm{i} 0}
$$

where $\mathrm{w}_{\mathrm{i} 0}, \mathrm{c}_{\mathrm{i} 0}, \mathrm{a}_{\mathrm{i} 0}, \mathrm{p}_{\mathrm{O}}$ is the wealth, amount of cash, and amount of assets for agent I and asset price at initial period, respectively. 


\section{Heterogeneity of agents}

In the literature which studies the asset markets, two types of agents are considered: fundamentalists and chartists. Fundamentalists are agents who make trading decisions based on estimates of the fundamental value of an asset. Unlike fundamentalists, chartists use the past price trends as a basis for decisions. Now, if an agent knows both types of information, namely the fundamental value of the asset and the history of price change rate, it is reasonable to assume that one will use both information to anticipate the future asset price. Therefore, in this model, we do not distinguish between fundamentalists and chartists. Instead, we assume that all agents know both types of information for the asset price and thus use both to predict the future price of an asset. Yet the weight for each type of information is different for all agents according to their beliefs. In sum, the prediction of the asset price for the next period is determined by current fundamental value of the asset and the history of the asset price change.

To consider the fundamental value of the asset into our model, it is necessary to define the fundamental value of the asset. In many previous papers which deal with fundamentalists in the asset market, fundamental values are assumed to be a constant (Chiarella and Iori 2002) or random walk process (Chiarella et al. 2009). In this paper, we assume that the fundamental value of the asset follows the random walk process with zero drift and volatility $\sigma^{2}$ to reflect the economic states, which are not constant. At time $t$, agents have the information for the fundamental value of the asset, $\mathrm{p}_{\mathrm{t}}^{\mathrm{f}}$ which determined by following equation and they use this information to predict the future price of the asset. Finally, we can define the fundamental value of the asset price at time $t$ as following.

$$
\mathrm{p}_{\mathrm{t}}^{\mathrm{f}}=\mathrm{p}_{\mathrm{t}-1}^{\mathrm{f}}+\varepsilon_{\mathrm{t}} \text { where } \varepsilon_{\mathrm{t}} \sim \mathrm{N}\left[0, \sigma^{2}\right]
$$

Regarding the information on the history of the price change, the level of the current asset price and the price change rate may be considered. This means the level of the asset price for the next period is determined by the level of the current price asset and the trend. Here, $\gamma$ is the weight for the price change rate. The information on the history of the price change which is available at time $t$ can be expressed as following.

$$
\mathrm{p}_{\mathrm{t}}^{\mathrm{c}}=\mathrm{p}_{\mathrm{t}}+\gamma\left(\frac{\mathrm{p}_{\mathrm{t}}-\mathrm{p}_{\mathrm{t}-1}}{\mathrm{p}_{\mathrm{t}-1}}\right)
$$

Finally, we have the prediction equation of the asset price for the next period, $\overline{\mathrm{p}}_{\mathrm{it}+1}$. This equation represents that agents anticipate the future asset price by using both types of information; fundamental value, $\mathrm{p}_{\mathrm{t}}^{\mathrm{f}}$ and the price change rate, $\mathrm{p}_{\mathrm{t}}^{\mathrm{c}}$. Here, $\alpha_{\mathrm{i}}$ means the weight of the fundamental value between two types of information, which is different for all agents.

$$
\begin{aligned}
& \overline{\mathrm{p}}_{\mathrm{it}+1}=\alpha_{\mathrm{i}} \mathrm{p}_{\mathrm{t}}^{\mathrm{f}}+\left(1-\alpha_{\mathrm{i}}\right) \mathrm{p}_{\mathrm{t}}^{\mathrm{c}} \\
& =\alpha_{\mathrm{i}}\left(\mathrm{p}_{\mathrm{t}-1}^{\mathrm{f}}+\varepsilon_{\mathrm{t}}\right)+\left(1-\alpha_{\mathrm{i}}\right)\left[\mathrm{p}_{\mathrm{t}}+\gamma\left(\frac{\mathrm{p}_{\mathrm{t}}-\mathrm{p}_{\mathrm{t}-1}}{\mathrm{p}_{\mathrm{t}-1}}\right)\right]
\end{aligned}
$$

where $0<\alpha_{i}<1, \gamma$ is constant for all $i$ and $t$

The trading rule is simple. Because agents examined in this paper pursue capital gains, they want to buy an amount of asset only if they expect that the price will rise above the current level. i.e., they can expect capital gains through asset trading. Otherwise, they choose to sell some of the assets they hold to prevent capital loss. 
The demand function for agents reflects this trading strategy. If agents expect the capital gains, $\overline{\mathrm{p}}_{\mathrm{it}+1}-\mathrm{p}_{\mathrm{t}}>0$, they choose to buy an amounts of the asset with a fixed fraction $\mathrm{g}$ of cash. With the same logic, if agents anticipate the capital loss, $\overline{\mathrm{p}}_{\mathrm{it}+1}-\mathrm{p}_{\mathrm{t}}<0$, they decide to sell g portions of assets they currently hold. In this model, because we impose constraint on borrowing and short-selling, agents can only trade assets when they have the cash for buying or assets for selling (Harras and Sornette 2011). One additional feature we need to notice is that when agents trade assets according to their prediction rules, they use only $g$ fractions of their cash or asset. During the simulation we set $g=0.1$. This reflects that agents hold both a risk free asset (cash) and risky assets in their portfolio, not confining these to one type of financial asset. The demand function could be summarized as following.

$$
\mathrm{D}_{\mathrm{it}}=\left\{\begin{array}{l}
\left(\overline{\mathrm{p}}_{\mathrm{it}+1}-\mathrm{p}_{\mathrm{t}}\right) g \mathrm{c}_{\mathrm{it}}=\left[\alpha_{\mathrm{i}}\left(\mathrm{p}_{\mathrm{t}}^{\mathrm{f}}-\mathrm{p}_{\mathrm{t}}\right)+\left(1-\alpha_{\mathrm{i}}\right) \gamma\left(\frac{\mathrm{p}_{\mathrm{t}}-\mathrm{p}_{\mathrm{t}-1}}{\mathrm{p}_{\mathrm{t}-1}}\right)\right] g \mathrm{gc}_{\mathrm{it}}, \text { if } \overline{\mathrm{p}}_{\mathrm{it}+1} \geq \mathrm{p}_{\mathrm{t}} \\
\left(\overline{\mathrm{p}}_{\mathrm{it}+1}-\mathrm{p}_{\mathrm{t}}\right) g \mathrm{a}_{\mathrm{it}}=\left[\alpha_{\mathrm{i}}\left(\mathrm{p}_{\mathrm{t}}^{\mathrm{f}}-\mathrm{p}_{\mathrm{t}}\right)+\left(1-\alpha_{\mathrm{i}}\right) \gamma\left(\frac{\mathrm{p}_{\mathrm{t}}-\mathrm{p}_{\mathrm{t}-1}}{\mathrm{p}_{\mathrm{t}-1}}\right)\right] g \mathrm{gat}_{\mathrm{it}}, \text { if } \overline{\mathrm{p}}_{\mathrm{it}+1}<\mathrm{p}_{\mathrm{t}}
\end{array}\right.
$$

\section{The existence of threshold: tipping point}

In this section, we consider the tipping point. Many previous studies, which deal with the financial markets, have pointed out that the existence of chartists and their strategy (technical trading) play a significant role in making volatility in asset markets (Joshi et al. 1998; Chiarella et al. 2009). That is to say, since they are speculators who seek excessive capital gains, they choose to buy additional assets if they believe that the price will rise even if the price is already high enough. During this process, the asset price reaches a very high level. At this point, there is a possibility that some agents might change their trading strategies from buying to selling due to a concern about a collapse of the asset price bubble if the price level increases above the level that agents believe to be the maximum. That means agents have expectations about the 'tipping point' for the asset price, and this level can vary among agents. To reflect this idea, we impose certain thresholds for the price level that agents believe to be the maximum. We model that this level, $\tilde{\omega}_{i}$, is randomly drawn from uniform distribution on the interval $[\underline{\Omega}, \bar{\Omega}]$ and is different for all agents.

The trading rule for considering the tipping point is similar to that of when we did not consider it. If the current level of the asset price is lower than the expectations for the tipping point and the price is expected to increase, then agents decide to buy some amount of assets. On the other hand, if agents expect the future price to fall or the price level is high enough compared with the level they believe to be the maximum, they will choose to sell an amount of assets to prevent capital loss. The trading rule and demand function when we consider the expectations about the 'tipping point' of agents are the following.

1) If $\mathrm{p}_{\mathrm{t}}<\tilde{\omega}_{1}$

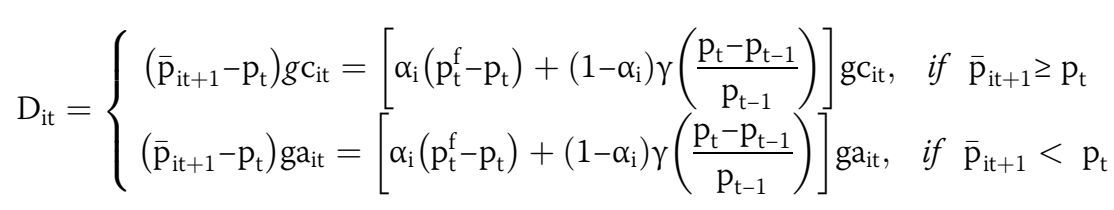

2) If $\mathrm{p}_{\mathrm{t}} \geq \tilde{\omega}_{1}$, 


$$
D_{\text {it }}=-g a_{i t}
$$

\section{Price determination}

Once all agents make decisions, the returns and new asset price are determined. Returns are determined by the excess demand and asset price is determined by the asset price of the last period and the return.

$$
\begin{aligned}
r_{t} & =\frac{1}{\lambda N} \sum_{i=1}^{N} D_{i t} \\
p_{t} & =p_{t-1} \exp \left(r_{t}\right)
\end{aligned}
$$

where $r(t)$ is the return at time $t$, and $\lambda$ is the relative impact of the excess demand upon the price (Harras and Sornette 2011).

\section{Cash and asset update}

Finally, cash and asset are updated as a result of trading. New cash amounts are determined by the cost for purchasing new assets subtracted from the amount of cash held by agents. The new asset amounts are determined by the amount of asset agents held in the last period and the demand for asset in this period.

$$
\begin{aligned}
\mathrm{c}_{\mathrm{it}+1} & =\mathrm{c}_{\mathrm{it}}-\mathrm{p}_{\mathrm{t}} \mathrm{D}_{\mathrm{it}} \\
\mathrm{a}_{\mathrm{it}+1} & =\mathrm{a}_{\mathrm{it}}+\mathrm{D}_{\mathrm{it}}
\end{aligned}
$$

\section{Simulation analysis}

In the simulation, we set the number $(\mathrm{N})$ of agents as 2,500, the initial amount of assets for each agent to $\mathrm{a}_{\mathrm{i} 0}=1$, the maximum amount of cash to $\overline{\mathrm{C}}=2$, the weight for fundamental value between two types of information to $\alpha_{i} \in[0,1]$ and the excess demand on the price of the asset to $\lambda=0.25$. We also fix the fraction of trading to $g=0.1$, that means agents use $0.1 \%$ of their cash or asset when they buy or sell the assets, respectively. We assume that the fundamental value follows random walk with initial value $\mathrm{p}_{0}^{\mathrm{f}}=0.53$, zero drift and the volatility $\sigma^{2}=10^{-3}$. The initial price of the asset, $p_{0}$ is set to 0.5 , and the expectations for the asset price at initial period are assumed to be randomly drawn from uniform distribution on the interval $[0,1]$.

For the simulation considering the expectations about the tipping point, we assume that the expectation for the tipping point, $\tilde{\omega}_{\mathrm{i}}$ is randomly drawn from uniform distribution on the interval $[\underline{\Omega}, \bar{\Omega}]$. Lower bound and Upper bound for the tipping point is fixed to $\underline{\Omega}=1$ and $\bar{\Omega}=2$, respectively. We additionally run simulations with higher number of $\bar{\Omega}$ from 2 to 3 and 4 to test the effect of the level of the expectations about the tipping point on the asset price dynamics. All parameter values are summarized in Table 1.

\section{Price dynamics}

In the basic simulation, we have considered two types of information, the fundamental value of the asset and the history of the price change rate. All agents in this simulation use both types of information but the weight for each component is different for all agents. The tipping point is not considered yet. Figure 1 shows asset price dynamics 
Table 1 Summary of the Parameters of the simulation

\begin{tabular}{lll}
\hline Description & Symbol & Value \\
\hline Number of agent & $N$ & 2500 \\
Initial amount of asset & $\mathrm{a}_{\mathrm{i}}$ & 1 \\
The maximum amount of cash agent can hold & $\mathrm{C}$ & 2 \\
Weight for fundamental value between two types of information & $\mathrm{a}_{\mathrm{i}}$ & $\mathrm{a}_{\mathrm{i}} \in[0,1]$ \\
Variance for random walk & $\sigma^{2}$ & $10^{-3}$ \\
Impact of the excess demand on the price & $\lambda$ & 0.25 \\
The fraction of trading & $\mathrm{g}$ & 0.1 \\
Weight on price change rate & $\mathrm{\gamma}$ & 1 \\
Initial fundamental value & $\mathrm{p}_{0}^{\mathrm{f}}$ & 0.53 \\
Initial asset price & $\mathrm{p}_{0}$ & 0.5 \\
Upper bound for threshold & $\bar{\Omega}$ & 2 \\
Lower bound for threshold & $\Omega$ & 1 \\
\hline
\end{tabular}

as a consequence of the behaviors of heterogeneous agents without considering the 'tipping point'. The asset price falls to 0.2 and rises to 1.8 .

\section{The 'tipping point' effect}

Next, to investigate the role of expectations about the 'tipping point' on the dynamics of asset price, we impose certain thresholds representing the expectations for the tipping point to each agent, and compare the two results where it is considered and not considered. In this basic simulation, the expectations for the tipping point of agents are randomly drawn from uniform distribution on the interval [1,2], and once it has been imposed for each agent, we assume that it has not changed over the time. Namely, it could be interpreted as the innate characteristics of agents. For example, the agent who has a small number of $\tilde{\omega}_{\mathrm{i}}$ which is close to 1 believes that the asset price will not increase to a very high level. As a result, he changes his trading rules quickly even at a relatively low price level.

As seen in Fig. 2, the existence of heterogeneous expectations for the tipping point can affect the dynamics of the price. Before the price attains the tipping point, the pattern of the price is similar to the case without it as shown in Fig. 1. However, after the asset price reaches above the tipping point level that many agents expect, there are

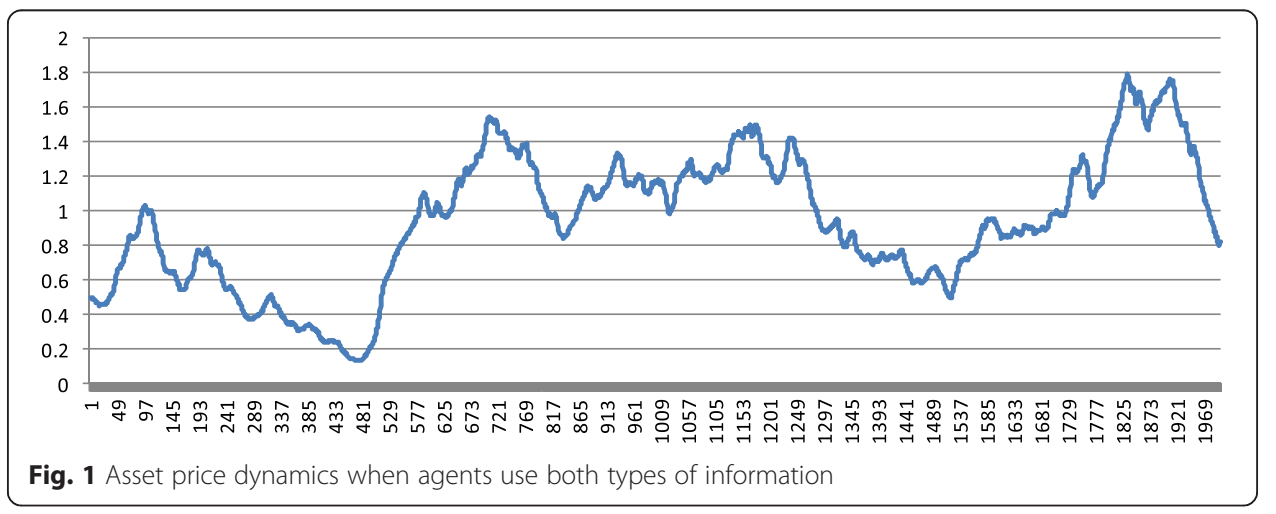




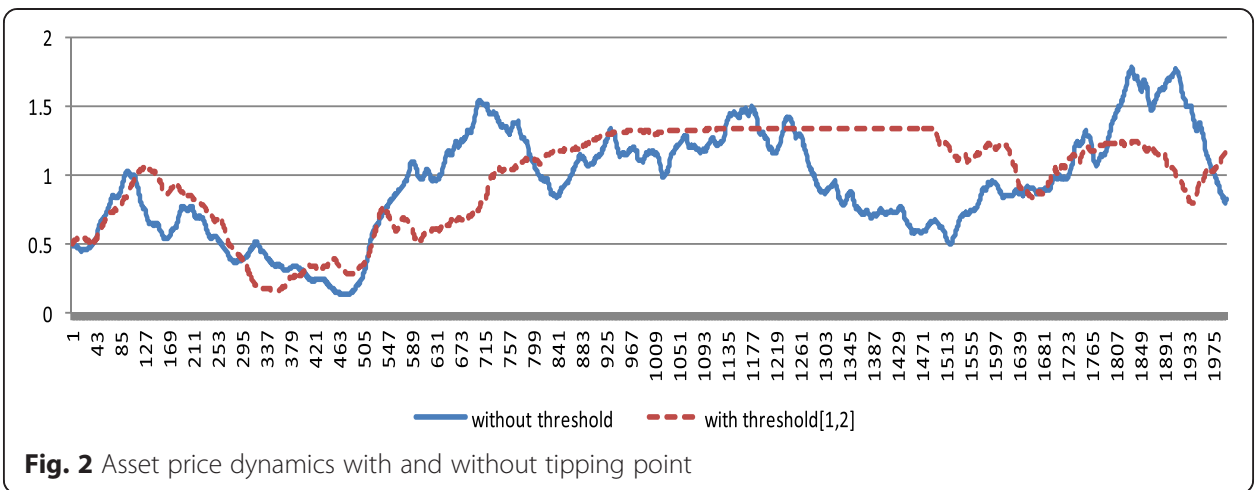

some agents who start to sell some amount of asset due to a concern about the possible collapse of the asset price. As a result, the price does not rise sharply, and seemingly flat intervals are detected. The reason why the seemingly flat intervals occur is simple. Since all agents are heterogeneous in their expectations about the tipping point level, when the price attains certain levels some agents who have smaller expectations for the tipping point than the current asset price level change their strategy and begin to sell a portion of assets they hold. However, simultaneously, the level of the price is still not high enough to change the strategy of some agents who have a higher level of expectation for the tipping point. Namely, even in the same price level, the decisions for trading assets will diverge depending on the tipping point level that each agent expects. As a result, price fluctuations are small and may even they appear flat.

In addition, we simulate such as changing the upper bound for the uniform distribution, $\bar{\Omega}$, from 2 to 3 and to investigate how the level of the expected tipping point can affect price dynamics and the results are shown in Fig. 3.

Through Fig. 3, we confirm that as the upper bound for the threshold get larger, the peak the price can attain become higher. Some flat intervals still appear because of the existence of the expectation about the tipping point and heterogeneity of it.

Taken all together, we can draw an initial conclusion about the role of heterogeneous tipping point of agents in asset markets; mainly it could play a role in mitigating the bubbles in financial markets and heterogeneity of this level prevents the price from falling too sharply.

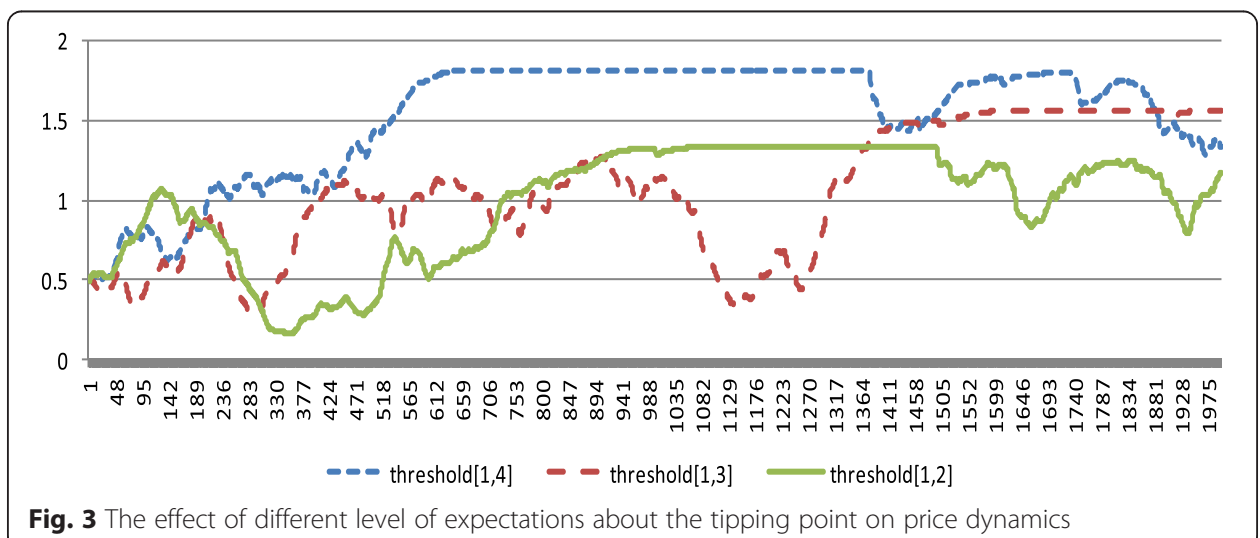


Impact of herding behavior with only one group

Now, extending the 'tipping point' experiment, we allow some agents to share the same expectations for the tipping point. For this simulation, we divide a population of agent into a single group and the rest, where we impose the same expectations about the tipping point to the agents belonging to this same group but different expectations among agents in the rest of the population. When a certain portion of agents share same beliefs about the tipping point, they make decision about their trading strategies collectively and thus they move in the same direction. The simulation results are shown in Fig. 4. Each figure represents the size of this group (in terms of its share in population) in which the affiliated agents share the same expectations about the threshold.

As shown in Fig. 4, as a result of this 'herding behaviors' of agents, we find that with the increasing size of the group, the interval with flat price tend to disappear, and that

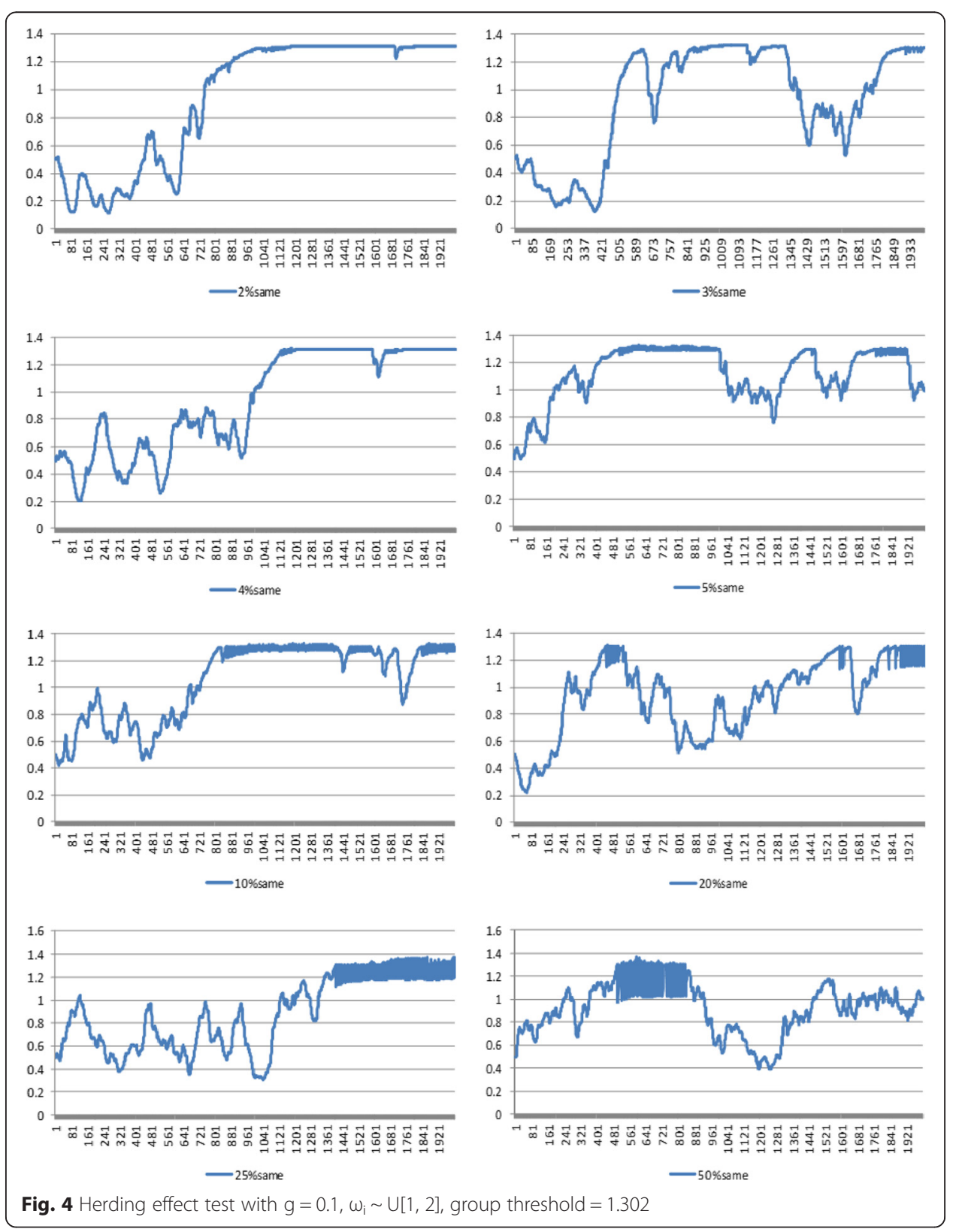


there are some periods (the part with very thick bands) where asset price fluctuates rapidly. By comparing the graphs with increased size of the group in Fig. 4, we also confirm that this impact of herding behavior is larger when more agents share the same belief about the tipping point.

\section{Herding behavior with more than one group with the equal size}

Now, we divide agents into several groups and impose the same belief about the tipping point to agents belonging to the same groups. Figure 5 reports the result of this simulation. As a result, similar to the herding effect test in section Impact of herding behavior with only one group, we could find some intervals where the asset price moves rapidly within a short period of time. In addition, by reducing the number of groups, the more agents share the same level, the higher price volatility emerges.

Comparing Figs. 4 and 5, we can see that even if a group of agents has the power to change the asset price in the market as they move at the same time, the pattern of the market price will be different depending on whether the rest of the agents maintain heterogeneity regarding the threshold or not. However, as the size of the group becomes larger, its effect on the market price also becomes more powerful. So, in this case, we can find some unstable intervals during which the asset price changes dramatically within a

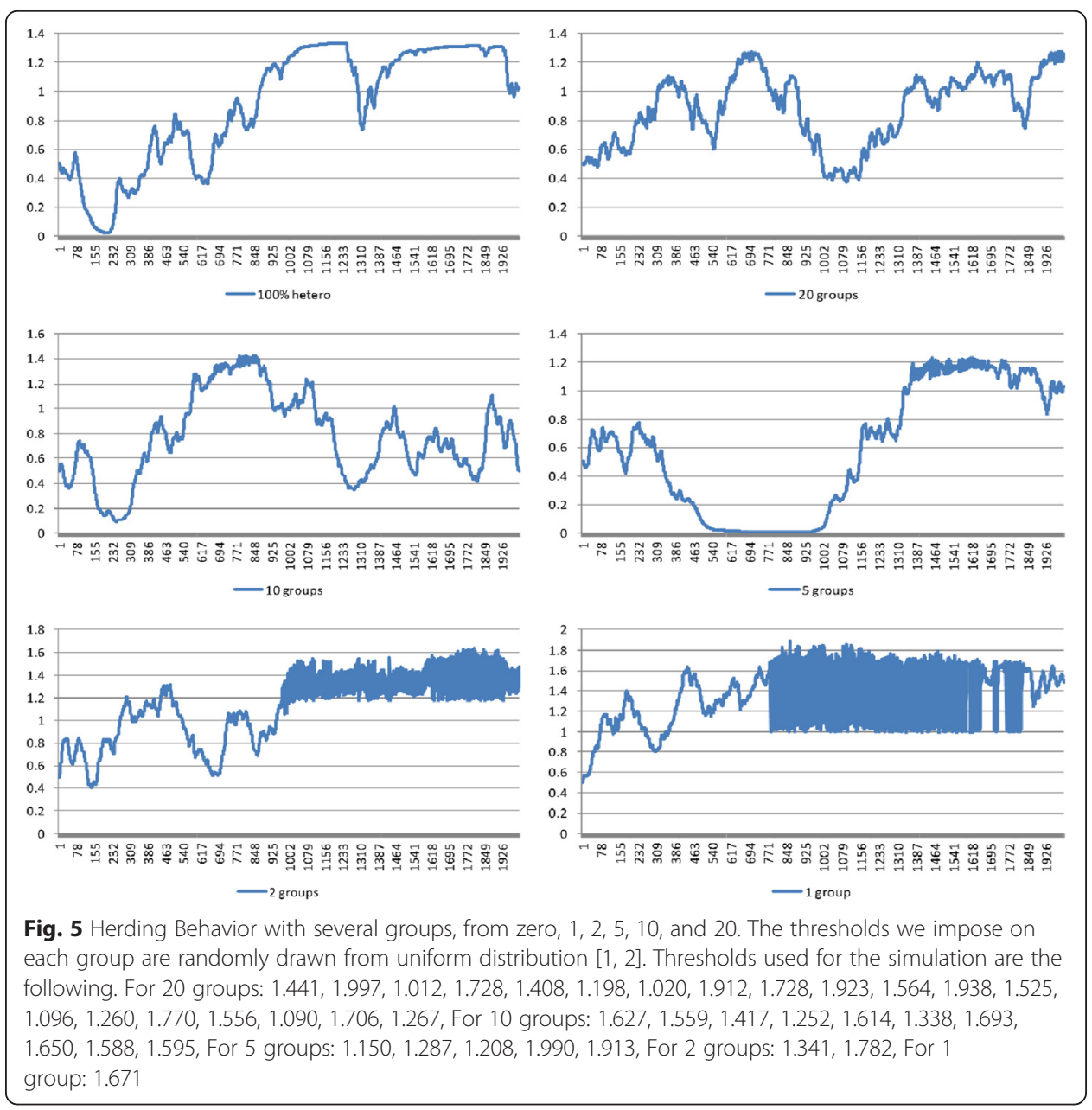


very short period of time. Especially, as shown in the last two graph of Fig. 5 (with only 1 or 2 group consisting of the half or whole population with a high degree of herding behavior), the price fluctuates very fast within a short period of time, and the collapse of the system is inevitable. Such 'system failure' interval also emerges with the case of 5 groups in Fig. 5 but with smaller vertical range of price fluctuations.

\section{Concluding remarks}

In this paper, we investigate conditions of financial instability such as bubbles and crashes in asset markets that created as a consequence of the behaviors of heterogeneous agents and their interactions, based on $\mathrm{ABM}$. In contrast to previous literatures which deal with financial market with mainly heterogeneous agents and their interactions based on ABM, we additionally considered the different expectations of agents about the 'tipping point' where price are expected to fall and investigate how the existence of 'tipping point' and the level affect the dynamics of asset price.

Our model makes contributions to demonstrating the main findings. First, before introducing the 'tipping point' to the model, we simulate the dynamics of asset price as a result of behaviors of heterogeneous agents in anticipating the future asset price based on ABM. We present the realistic looking dynamics of asset price as a result of the heterogeneous expectations for the future price of agents and their interactions through the market price.

Second, for a more realistic analysis, we consider the different expectations about the 'tipping point' of agents in the model. As already mentioned, agents in this model choose the best actions to maximize their capital gains and such behaviors in asset markets push the asset price to a higher level. However, during the process, some agents might change their trading strategies from buying to selling due to concern about a possible collapse of the asset price if the price level surges above a certain level. To reflect this aspect, we impose a threshold which represents the agent's expectation about the tipping point. The level is different for all agents. The simulation results confirm that the existence of heterogeneous expectations about the tipping point and the level affect price dynamics and the maximum level that the asset price can attain. Some seemingly flat intervals appear instead of collapse in asset price because the decisions for trading assets will diverge depending on the tipping point level that each agent expects. Also, the maximum level the price can reach becomes higher as the level of expectations about tipping point get larger.

Lastly, we investigate how the dynamics of asset price could be changed when some portion of agents share the same expectations for the tipping point. To analyze this 'herding effect', we conducted two additional simulation experiments. In one, we made a group, and set the same level of the tipping point for the agents in the group. For the other agents we gave them heterogeneous levels that we used in the basic test. In the second experiment, we divided agents into groups and imposed the same belief about the tipping point for agents belonging to the same group. In both cases, because agents in the same group change their trading behavior at the same time, they have a power to move the market price. As a final outcome, we discovered some unstable intervals where asset price fluctuated rapidly in the short term. In addition, by reducing the number of groups, as more agents share the same expectations for the tipping point, higher price volatility emerges. 


\section{Endnotes}

${ }^{1}$ For more details, see Cooper (2008).

${ }^{2}$ See Gilbert (2007).

\section{Competing interests}

We do not have any competing interests.

\section{Authors' contribution}

SL and KL set up the model, simulated the model and participated in writing the manuscript. Both authors read and approved the final manuscript.

Received: 3 August 2015 Accepted: 25 August 2015

Published online: 15 September 2015

References

Arthur WB, Holland J, LeBaron B, Palmer R, Tayler P. Asset pricing under endogenous expectations in an artificial stock market. In: Arthur WB, Durlauf S, Lane D, editors. The Economy as an Evolving Complex System II, Addison-Wesley, Reading, MA. 1997. p. 15-44.

Buchanan M. Meltdown Modeling: Could Agent-Based Computer Models Prevent Another Financial Crisis? Nature 460. 2009. p. 680-2.

Bullard J, Duffy J. Learning and excess volatility. Macroecon Dyn. 2001;5:272-302.

Chen $\mathrm{SH}$, Yeh $\mathrm{CH}$. Evolving traders and the business school with genetic programming: A new architecture of the agent-based artificial stock market. J Econ Dyn Control. 2001;25:363-93.

Chiarella C, lori G. A simulation analysis of the microstructure of double auction markets. Quantitative Finance. 2002;2:346-53.

Chiarella C, Dieci R, Gardini L. Asset price and wealth dynamics in a financial market with heterogeneous agents. J Econ Dyn Control. 2006;30:1755-86.

Chiarella C, lori G, Perello J. The impact of heterogeneous trading rules on the limit order book and order flows. J Econ Dyn Control. 2009:33:525-37.

Colander D, Goldberg M, Hass A, Juselius K, Kirman A, Lux T, et al. The Financial Crisis and the Systemic Failure of the Economics Profession. Critical Review. 2009;21:249-67.

Cooper G. The Origin of Financial Crises: Central Banks, Credit Bubbles and the Efficient Market Fallacy. Petersfield: Harriman House; 2008.

Ehrentreich, N (2004) A corrected version of the Santa Fe Institute Artificial Stock Market Model. Working paper, University of Halle-Wittenberg: Germany.

Farmer JD, Foley D. The economy needs agent-based modeling. Nature. 2009;460(August 6):685-6.

Gilbert, N (2007) Agent-based Models. In: Series: Quantitative Applications in the Social Sciences, vol. 153. Sage Publications.

Harras G, Sornette D. How to grow a bubble: model of myopic adapting agents. J Econ Behav Organ. 2011;80:137-52.

Joshi S, Parket J, Bedau MA. Technical trading creates a prisoner's dilemma: results from an agent-based model, Working paper 98-12-115E, Santa Fe Institute. 1998.

LeBaron B. Evolution and time horizons in an agent based stock market. Macroecon Dyn. 2001;5:225-54.

LeBaron B. Agent-based Financial Markets: Matching Stylized Facts with Style. In: Colander D, editor. Post Walrasian Macroeconomics: Beyond the DSGE Mode. Cambridge: Cambridge University Press; 2006. p. 221-35.

LeBaron B, Arthur WB, Palmer R. Time series properties of an artificial stock market. J Econ Dyn Control. 1999;23:1487-516.

Lettau M. Explaining the facts with adaptive agents: The case of mutual fund flows. J Econ Dyn Control. 1997;21:1117-47.

Malek B, Ezzeddine A. Agent-Based Approach to asset price fluctuations and excess volatility: an experimental investigation. Middle Eastern Finance Econ. 2011;12:159-73.

Palmer RG, Arthur WB, Holland JH, LeBaron B, Tayler P. Artificial economic life: a simple model of a stockmarket. Physica D. 1994;75:264-74.

The economist. Agents of change. 2010.

Yoon M, Lee K. Agent-based and "History-Friendly" Models for Explaining Industrial Evolution. Evolutionary Institu Econ Review. 2009;6:45-70.

\section{Submit your manuscript to a SpringerOpen ${ }^{\circ}$ journal and benefit from:}

- Convenient online submission

- Rigorous peer review

- Immediate publication on acceptance

- Open access: articles freely available online

- High visibility within the field

- Retaining the copyright to your article 